\title{
DESENVOLVIMENTO DE UMA PROPOSTA DE EDUCAÇÃO SEXUAL PARA ADOLESCENTES
}

\author{
Development of a proposal \\ for sex education for adolescents
}

\author{
Rúbia de Aguiar Alencar ${ }^{1}$ \\ Lucía Silva ${ }^{2}$ \\ Fábio Arlindo Silva ${ }^{3}$ \\ Renato Eugênio da Silva Diniz ${ }^{4}$
}

\begin{abstract}
Resumo: O objetivo geral do presente estudo foi descrever a experiência de construção e aplicação de uma proposta pedagógica no campo da educação sexual, fundamentada em algumas premissas contidas na concepção de Paulo Freire, visando atender adolescentes de uma comunidade carente do interior paulista. A partir dos questionamentos iniciais levantados pelos jovens foram realizados quatro encontros focando questões sobre sexualidade, anatomia e fisiologia humana, métodos anticoncepcionais e DST/Aids. Com a realização desse trabalho, os jovens tiveram oportunidade de participar de um processo educativo que possibilitou, pelo resgate de suas próprias experiências e crenças, a reflexão sobre sua autonomia na vivência de uma sexualidade saudável, respeitando a si próprio e ao outro.
\end{abstract}

Palavras-chave: Proposta pedagógica. Educação em saúde. Educação sexual. Adolescência.

\begin{abstract}
The general objective of this study was to describe the experience of the development pedagogy for sex education, based on assumptions contained in the work of Freire, seeking to assist adolescents from the periphery of a city in the interior from São Paulo. We opted for an action-research based pedagogic model from Freire. Starting initial questioning of the youths four interviews were carried out concentrating on questions about sexuality, anatomy and human physiology, birth-control methods and sexually transmitted diseases. With the completion of this work, the youths had the opportunity to participate in an educational process through the examination of their own experiences and beliefs, making it possible to reflect about their autonomy within the experiences of a healthy sexuality, one which respects itself and values the other.
\end{abstract}

Key words: Pedagogical proposal. Health education. Sexual education. Adolescence.

\footnotetext{
${ }^{1}$ Mestre em Enfermagem Psiquiátrica e Ciências Humanas; docente, Centro Universitário Nove de Julho, Faculdade Marechal Rondon (UNINOVE/FMR). São Manuel, SP. < rubia_enf@hotmail.com>

${ }^{2}$ Doutoranda em Enfermagem; docente, UNINOVE/FMR. São Manuel, SP. <lucia_funes@yahoo.com.br>

${ }^{3}$ Doutor em Zootecnia; docente, Departamento de Química e Bioquímica, Instituto de Biociências, Unesp, campus de Botucatu (IBB/Unesp). Botucatu, SP. < fabioarlindo@ibb.unesp.br>

${ }^{4}$ Doutor em Educação; docente, Departamento de Educação, IBB/Unesp. Botucatu, SP.

<rdiniz@ibb.unesp.br>

${ }^{3}$ Rua João de Oliveira, 1071

Altos do Paraíso - Botucatu, SP

18.610-000 


\section{Introdução}

A adolescência é a fase de transição entre a infância e a idade adulta, marcada por transformações anatômicas, fisiológicas, psicológicas e sociais. É nesse período que ocorre o encontro de um núcleo de permanência e de estabilidade em si mesmo, denominado identidade, e sua busca por parte dos jovens pode produzir uma série de manifestações inquietantes, entre elas aquelas relacionadas ao exercício da sexualidade (PINTO, 1997).

Hercowitz (2002) considera importante o desenvolvimento da sexualidade para o crescimento do indivíduo em direção a sua identidade adulta, inserção na estrutura social e determinação de sua auto-estima e relações afetivas. Contudo, as mudanças no comportamento dos adolescentes em relação à sexualidade exigem atenção cuidadosa por parte dos pais e profissionais, devido às repercussões que incluem as vulnerabilidades relacionadas à saúde reprodutiva.

Nos dias de hoje, pode-se observar que os jovens iniciam cada vez mais cedo a atividade sexual, adotando práticas e comportamentos que os deixam sob maior risco de infecção pelo vírus da Síndrome da Imunodeficiência Adquirida (Aids) - o HIV - e outras doenças sexualmente transmissíveis (DST). Daí a importância de se abordarem questões sobre sexualidade antes mesmo de iniciar uma discussão sobre a temática dessas doenças propriamente ditas (BRASIL, 1997a).

O crescente aumento dos casos de infecção pelo HIV entre os adolescentes, a ineficiência dos registros de casos de DST, o pouco conhecimento dos jovens em assuntos relacionados à sexualidade e os programas educacionais inadequados são questões preocupantes e que devem ser levadas em consideração em relação à prevenção das DST e Aids (BRASIL, 1997b). Diante disso, Galvão, Ferreira e Alencar (2003) trazem que as ações em saúde relacionadas à prevenção das DSTs, implementadas de forma coerente e adaptadas para cada comunidade, têm sido uma das medidas de que se pode lançar mão para conter a propagação dessas doenças.

Ainda em relação à educação sexual, o Ministério da Educação, por meio dos Parâmetros Curriculares Nacionais (PCN) inclui a orientação sexual entre os temas transversais nas diversas áreas do conhecimento, com finalidade de impregnar toda a prática educativa com as questões da orientação sexual (BRASIL, 1997c).

Embora haja um consenso entre os estudiosos sobre a necessidade de se promover a discussão de questões referentes à sexualidade, na prática, educadores e pais ainda parecem apresentar dificuldades em abordar o tema com os jovens. Além disso, nota-se que nas escolas os chamados temas transversais, entre eles a educação sexual, não são tratados de forma a integrar os diferentes saberes, ou seja: a interdisciplinaridade não é contemplada. Isso pode ser constatado pelo fato de se acreditar que, dentro da instituição escolar, o professor de biologia é aquele que mais reúne condições para atender a demanda dos jovens com os questionamentos sobre sexualidade. Entretanto, Sayão (1997) argumenta que se o professor tem a disponibilidade pessoal para se responsabilizar pelo trabalho, sua área de conhecimento não é o ponto mais importante.

O fundamental para a abordagem educacional é que esta seja trabalhada e discutida sob o enfoque da integralidade que, de acordo com Machado et al. (2007), trata-se de abordar os indivíduos, grupos e coletividade tendo o usuário como sujeito histórico, social e político, articulado ao seu contexto familiar, ao meio ambiente e à sociedade na qual se insere. 
Desenvolvimento de uma proposta de educação sexual...

Os autores acrescentam, ainda, que a educação em saúde como processo político-pedagógico requer o desenvolvimento de um pensar crítico e reflexivo, permitindo desvelar a realidade e propor ações transformadoras, enquanto sujeito histórico e social capaz de propor e opinar nas decisões de saúde para o cuidar de si, de sua família e da coletividade.

Outra questão sobre a educação sexual que merece destaque é a hostilidade com que a escola trata as manifestações da individualidade e da sexualidade dos jovens, adotando procedimentos despersonalizadores, como o cumprimento de horários impessoais para a realização de todas as atividades, e não considerando seu papel de construir individualidades, ou identidades e que esta é uma maneira indireta de contribuição ao amadurecimento da sexualidade juvenil (PINTO, 1997).

Em relação à questão, Bueno (2001) afirma que desde a década de 1980 a educação nacional vem passando por reflexões políticas e filosóficas acerca da realidade. Com isso, educadores têm buscado maneiras alternativas para a melhoria do ensino. No entanto, alguns professores ainda se mantêm estagnados no tempo, devido aos valores arcaicos e às condutas rígidas que assumem no seu cotidiano profissional.

De acordo com Pinto (1997), para ensinar adolescentes é necessário que haja a "subjetivação do conhecimento", ou seja, a transformação do conhecimento em caso pessoal, a vinculação entre o conteúdo proposto e a vida cotidiana do jovem. Desse modo, as intervenções realizadas por parte dos profissionais, tanto da área da educação como da saúde, devem levar em consideração os contextos familiar e social nos quais o jovem está inserido, a fim de compreender crenças e valores que permeiam sua vivência.

Sexualidade, família e escola (ou qualquer instituição que se dedique à educação), devem ser pensadas a partir do princípio da "não-exclusão", ou seja, sistemas que devem interagir entre si por meio de vinculação, união e respeito pelas diferenças (MEIRELLES, 1997).

Partindo das considerações apresentadas, a pedido do Serviço Social responsável pelo Programa SOS Bombeiro - Resgate da Cidadania, aceitou-se o desafio de desenvolver um programa educativo em sexualidade e DST/Aids junto aos adolescentes da comunidade assistidos pela instituição. O objetivo geral do presente estudo foi descrever a experiência de aplicação de uma proposta pedagógica no campo da educação sexual, visando atender adolescentes de uma comunidade carente do interior paulista, com foco em questões sobre sexualidade e DST/Aids. Especificamente, buscou-se levantar as dúvidas dos adolescentes sobre os temas, construir um plano de ação para o desenvolvimento dos conteúdos de seu interesse, envolvendo-os no desenvolvimento dos conteúdos de forma participativa e dialógica.

\section{Metodologia}

\section{O referencial pedagógico}

O estudo foi baseado no modelo pedagógico que se fundamenta na educação conscientizadora/problematizadora, sustentada pela metodologia participativa e dialogal, que favorece uma relação crítica e transformadora (FREIRE, 1996a). Para Freire (2000, 1996a), o ser humano é histórico, está submerso em condições espaço-temporais e, quanto mais refletir de maneira crítica sobre sua existência, mais poderá influenciar-se e tornar-se mais livre. 
A seguir, apresentam-se alguns conceitos formulados por Freire e amplamente utilizados nas áreas da educação e saúde.

A problematização supõe ação transformadora, é inseparável do ato cognoscente e de situações concretas e o conteúdo elaborado refere-se ao contexto, às situações vividas e possibilita que o educador chame o educando a refletir sobre a realidade de forma crítica (FREIRE, 1996a).

Diálogo é conteúdo da forma de ser próprio à existência humana. A educação é diálogo e comunicação, visto que não significa transferir saber e conhecimento e, sim, encontro de sujeitos interlocutores que buscam a significação dos significados (FREIRE, 2001, 1996b).

A liberdade pode ser definida como uma conquista e exige busca permanente, existindo apenas no ato responsável de quem a faz (FREIRE, 1996a).

Conscientização é uma inserção crítica na história, na qual o homem assume uma posição de sujeito capaz de transformar o mundo (FREIRE, 2000).

$\mathrm{Na}$ literatura que privilegia o tema são descritas iniciativas educativas tendo o referencial de Freire como eixo estruturador (TORRES, O' CADIZ, WONG, 2002), entre elas a que o próprio educador coordenou quando foi secretário da Educação do município de São Paulo (FREIRE, 1995). Em tese de doutorado desenvolvida por Silva (2004), a autora busca resgatar e analisar práticas educativas, abordando, inclusive, a Aids e como este tornou-se um tema gerador para ser trabalhado com alunos do ensino fundamental.

\section{O referencial metodológico}

Adotou-se como percurso metodológico a pesquisa do tipo experimental, por meio da abordagem qualitativa. Esta abordagem pode ser definida como aquela que se preocupa com um nível de realidade que não pode ser quantificado, trabalhando com o universo de significados, motivos, aspirações, crenças, valores e atitudes que, por sua vez, correspondem a um espaço mais profundo das relações, dos processos e fenômenos que não podem ser reduzidos à operacionalização de variáveis (MINAYO, 1994).

\section{O local do estudo e os atores participantes}

O trabalho foi realizado no Programa SOS Bombeiro - Resgate da Cidadania, localizado na Vila Real, bairro popular coberto por uma Unidade de Saúde da Família no município de Botucatu - SP, no decorrer do $2^{\circ}$ semestre de 2004. Participaram duas enfermeiras e um licenciado em Ciências Biológicas - autores da pesquisa, e 58 jovens (42 meninos e 16 meninas), que apresentaram autorização dos pais ou responsáveis.

Foram excluídos os jovens que não concordaram em participar, em qualquer momento da realização do trabalho, e os que não apresentaram o consentimento dos pais ou responsáveis. Contudo, vale ressaltar que foram assegurados os direitos dos adolescentes em relação à participação, sem restrição no desenvolvimento das atividades do Programa. 
Desenvolvimento de uma proposta de educação sexual...

\section{Plano de ação para realização da proposta pedagógica}

Desenvolveu-se inicialmente uma investigação exploratória no sentido de identificar os questionamentos dos adolescentes relacionados à sexualidade e DST/Aids, uma vez que, de acordo com Lourencini Júnior (1997), as questões a serem abordadas em relação à sexualidade devem surgir do interesse e do cotidiano dos jovens.

Para tal, utilizou-se uma caixa lacrada, que permaneceu no local da pesquisa por uma semana, na qual os jovens deixaram por escrito, sem a necessidade de se identificarem, questionamentos e sugestões de trabalho tendo, dessa maneira, participação ativa no conteúdo programático elaborado e na forma como o mesmo poderia ser trabalhado. As dúvidas identificadas estavam relacionadas à anatomia (masculina e feminina), fisiologia (masturbação, menstruação, reprodução humana, gravidez), métodos anticoncepcionais e doenças sexualmente transmissíveis.

As sugestões de trabalho apresentadas pelos adolescentes foram: aulas, uso de figuras e fotos, preservativo masculino e brincadeiras. A partir daí foi possível planejar a abordagem dos temas em quatro encontros:

\section{Sexualidade, anatomia e fisiologia humana}

- Conteúdos abordados: definição de sexo e sexualidade, anatomia feminina e masculina, masturbação, menstruação, reprodução humana e gravidez.

- Estratégias adotadas: dinâmica com bexigas e música (cada participante segura uma bexiga contendo no interior um papel com o nome de um dos órgãos genitais e o coloca no local correspondente, sobre um quadro de anatomia humana); aula expositiva dialogada com verbalização de experiências e esclarecimentos de dúvidas e a exposição dos filmes "Os melhores desejos" e "Música para dois", que abordam o relacionamento e a sexualidade entre adolescentes.

- Recursos utilizados: a) humanos: adolescentes da instituição, duas enfermeiras, um licenciado em Ciências Biológicas; b) materiais: bexigas e um conjunto de quadros imantados do aparelho reprodutor feminino e masculino com as respectivas figuras ilustrativas dos processos de menstruação, reprodução e gestação; c) audiovisuais: CD e fita de vídeo; d) equipamentos: aparelho de som, televisão e videocassete.

\section{Métodos anticoncepcionais/proteção contra DST}

- Conteúdos abordados: formas de práticas sexuais, gravidez indesejada, abordagem geral das DST e Aids, preservativo feminino e masculino (cuidados antes e após o uso), outros métodos anticoncepcionais (diafragma, DIU, gel espermicida, anticoncepcional oral e injetável e contracepção de emergência) e métodos anticoncepcionais inadequados (coito interrompido e tabelinha).

- Estratégias adotadas: aula expositiva dialogada com verbalização de experiências e esclarecimento de dúvidas; colocação de preservativo feminino em modelo pélvico feminino e colocação de preservativo masculino em modelo peniano. 
- Recursos utilizados: a) humanos: adolescentes da instituição, duas enfermeiras, um licenciado em Ciências Biológicas; b) materiais: quadro ilustrativo contendo os métodos anticoncepcionais, preservativos masculino e feminino, modelo peniano de borracha e modelo pélvico de acrílico do aparelho reprodutor feminino.

\section{Doenças Sexualmente Transmissíveis e Aids}

- Conteúdos abordados: conceitos de Aids e DST, principais tipos de DST (gonorréia, candidíase, tricomoníase, condiloma acuminado, herpes genital, clamídia, sífilis, cancro mole, linfogranuloma, vaginose, donovanose, chato e hepatite B), sinais e sintomas das DST, modos de transmissão e prevenção.

- Estratégias adotadas: aula expositiva dialogada com verbalização de experiências e esclarecimentos de dúvidas; exposição do filme "Realidade não virtual" (aborda a prevenção das DST e Aids com jovens em situação de exclusão social, utilizando elementos da cultura "Hip-Hop" e grafite).

- Recursos utilizados: a) humanos: adolescentes da instituição, duas enfermeiras, um licenciado em Ciências Biológicas; b) materiais: álbum grande ilustrado sobre DST/Aids; c) audiovisuais: fita de vídeo; d) equipamentos: televisão e videocassete.

\section{Desenvolvimento de material educativo pelos atores participantes}

- Conteúdos abordados: todos os conteúdos abordados nos temas anteriores.

- Estratégias adotadas: os jovens, divididos em pequenos grupos mistos (meninos e meninas), escolhem uma atividade de finalização do trabalho (dramatização, confecção de material educativo etc).

- Recursos utilizados: a) humanos: adolescentes da instituição, duas enfermeiras, um licenciado em Ciências Biológicas; b) materiais: cartolinas, canetinhas coloridas, revistas, cola e tesoura; c) audiovisual: CD; d) equipamentos: aparelho de som.

Para a execução do conteúdo programático, inicialmente os adolescentes foram divididos em seis grupos de oito a 12 sujeitos cada: quatro grupos de trabalho com meninos e dois grupos com meninas, para abranger os interesses mais específicos do ponto de referência de gênero.

Para contemplar todos os temas de interesse dos jovens, fez-se necessário realizar 18 encontros (três com cada um dos seis grupos) e mais dois encontros finais com dois grandes grupos (meninos e meninas juntos, um grupo para a turma da manhã e outro para a turma da tarde). Neles os jovens optaram pela atividade de encerramento do estudo (dramatização, confecção de cartazes educativos etc), com base nos conteúdos trabalhados no decorrer das atividades anteriores. Ressalta-se que cada encontro teve duração média de duas horas.

Durante as atividades, os três pesquisadores se dividiram, ficando dois na coordenação (mediando discussões, conduzindo as dúvidas surgidas, organizando o material a ser exposto e utilizado etc), enquanto o terceiro fazia uso da técnica da observação participante, que visa obter informações da realidade dos atores sociais em seus próprios contextos (NETO, 1994). Como instrumento para registrar percepções, questionamentos e informações importantes durante as interações utilizou o diário de campo, registrando-se notas breves, como palavras e frases, de modo que viessem a possibilitar a reconstrução da situação observada. 
Desenvolvimento de uma proposta de educação sexual...

Ao final de cada encontro foi realizada uma avaliação na qual os jovens verbalizaram conceitos e práticas apreendidos; as atividades desenvolvidas também foram avaliadas por escrito pelos jovens. Para finalizar, a organização e a análise da pesquisa foram realizadas à luz de literatura sobre o tema.

\section{Resultados e discussão}

No início de cada encontro foi realizada uma breve explicação sobre o tema a ser abordado para, em seguida, começarem as discussões, reflexões e verbalizações de experiências, tendo como norte principal as questões levantadas pelos próprios jovens, como fonte problematizadora e motivadora.

O primeiro encontro teve como objetivos: a) compreender o significado de sexo/ sexualidade, características físicas e emocionais do homem e da mulher, anatomia e fisiologia feminina e masculina; e b) criar um ambiente de modo a estimular a reflexão da própria sexualidade de cada jovem.

Este foi, para todas as turmas, um encontro permeado por um ambiente de bastante descontração. Acredita-se que isso tenha sido facilitado pela dinâmica inicial, envolvendo música e bexiga, introduzindo as discussões sobre sexualidade, anatomia e fisiologia humana.

Nos grupos masculinos, os questionamentos eram basicamente dirigidos à anatomia feminina e masculina e ao processo de gravidez. Muitos também questionaram sobre a masturbação, no sentido de validarem o valor de transgressão ou pecado que é atribuído à prática por seus pais ou outros colegas. Convém ressaltar que no processo contínuo de busca dos sentidos da sexualidade, o indivíduo sofre as influências diretas da "cultura da sexualidade", fazendo com que o adolescente reproduza o "modo de pensar" advindo do modelo familiar, dos meios de comunicação, da religião e da escola (CARDOSO e COCCO, 2003; LOURENCINI JÚNIOR, 1997).

Já as meninas, além das curiosidades sobre o corpo feminino e masculino, tiveram interesse de discutir principalmente a questão da menstruação, da gravidez e da virgindade.

$\mathrm{Na}$ avaliação escrita do encontro os jovens trouxeram que era muito bom terem um espaço para os esclarecimentos das dúvidas relacionadas ao sexo e também fizeram desenhos do órgão reprodutor feminino e masculino, similares aos que haviam visto nos quadros expostos durante a atividade.

Os objetivos do segundo encontro foram: a) reconhecer as diferentes práticas sexuais, os riscos da prática sexual sem proteção ou com métodos inadequados (gravidez indesejada, DST/Aids) e conhecer os métodos anticoncepcionais; e b) propiciar um espaço para reflexão dos adolescentes sobre seu comportamento sexual, suas crenças e seus valores.

A abordagem das diferentes práticas sexuais causou muitos risos e certa timidez, principalmente entre os meninos. Os jovens verbalizaram intensamente sobre a prática da sexualidade em sua comunidade, identificando como nem sempre adequado o comportamento de exercitá-la sem proteção ou com parceiros eventuais. Lima et al. (2004) definem o "ficar" como uma prática cujos sentidos se estruturam em torno do não compromisso, da eventualidade e da atração física, permitindo a diversificação das parcerias sexuais e maior freqüência das relações, aumentando a possibilidade de fazer sexo sem proteção. 
$\mathrm{Na}$ atividade de colocação do preservativo no modelo peniano, inicialmente a maioria mostrou-se constrangida. Porém, à medida que os primeiros jovens se propuseram a realizá-la, os demais também o quiseram e, por fim, muitos realizaram-na por mais de uma vez. Apenas dois meninos e duas meninas não quiseram realizar esta atividade.

Ao avaliarem esse encontro, os adolescentes relataram o quanto foi proveitoso conhecer todos os métodos contraceptivos e de prevenção para as DST, pois esta informação traz benefícios para sua própria saúde, e que gostaram muito da oportunidade de aprender, na prática, a colocação correta do preservativo masculino.

O terceiro encontro objetivou: a) conceituar Aids e DST, citando as mais comuns; b) descrever sinais e sintomas das doenças; e c) trabalhar as dúvidas dos jovens lidando com preconceitos e tabus.

Meninos e meninas mostraram-se inicialmente "chocados" com o álbum sobre DST que continha fotos ilustrativas das doenças. Alguns viraram o rosto para não olhar o material, alegando ser "feio". Aos poucos, foram se aproximando e passaram a examinar o material atentamente, demonstrando preocupação, inclusive, com as pessoas portadoras dessas doenças. A partir daí começou-se uma discussão acerca do preconceito em relação às mesmas.

Ao assistirem ao filme "Realidade não virtual", os jovens identificaram-se com as músicas e situações dos personagens no lar e com os amigos. Antes mesmo do término, interagiram entre si discutindo atitudes de risco dos personagens.

Ao final desse encontro os adolescentes relataram que já tinham ouvido falar da Aids, mas que não tinham quase nenhum conhecimento sobre as DST. Também trouxeram que gostaram do filme por apresentar uma realidade muito próxima a eles.

Os objetivos do quarto e último encontro foram: a) promover interação entre meninos e meninas; b) escolha de uma atividade por parte dos jovens para o encerramento de todos os encontros; e c) apresentação ou exposição da atividade escolhida.

Este encontro foi realizado com todos os adolescentes participantes, agora meninas e meninos juntos. Propôs-se que escolhessem uma maneira para passarem a todos os presentes o conhecimento apreendido até então (dramatização ou confecção de material educativo, por exemplo) e todos optaram pela confecção de cartazes educativos. Assim, o grupo foi dividido em grupos mistos e menores de trabalho, que confeccionaram cartazes sobre os diversos temas. Cada pequeno grupo organizou-se da maneira que lhe pareceu melhor: quem iria escolher e separar o material a ser utilizado, fazer os recortes de revista, desenhar, escrever e apresentar o material aos demais.

Ao final, todos os grupos se apresentaram de maneira bastante descontraída., abordando, de maneira bem criativa, praticamente todos os temas dos encontros anteriores: frases de alerta, propagandas para a prática do sexo seguro, caricaturas de casais jovens e adultos promovendo o uso dos preservativos etc.

Os jovens gostaram da oportunidade de produzir o material educativo e solicitaram que ele fosse exposto na instituição para que também pudessem ver o que havia sido produzido pelos jovens do outro turno. 
Desenvolvimento de uma proposta de educação sexual...

\section{Considerações finais}

Com base nos pressupostos teóricos de Paulo Freire, as atividades realizadas permitiram que os jovens participassem da construção de um processo educativo que possibilitou, mediante resgate de suas próprias experiências e crenças, a reflexão e crítica sobre sua autonomia na vivência de uma sexualidade saudável, respeitando a si próprio e ao outro.

Assim, acredita-se que os objetivos iniciais foram totalmente alcançados, visto que foi possível construir e aplicar uma proposta pedagógica na qual todos os envolvidos tiveram uma participação ativa.

A experiência mostrou que é possível, de acordo com Lourencini Júnior (1997), trazer para os encontros a ressignificação da sexualidade, na qual as dimensões humanas "espécie biológica" e "espécie cultural" não se encontram no confronto e, sim, em sua unidade.

Também cabe ressaltar que o material educativo disponível na Secretaria de Saúde do município mostrou-se muito funcional e interativo.

Para finalizar, concordamos com Vitiello (1995) ao trazer que educar significa formar alguém, proporcionando condições para que este cresça consciente e responsável pelos seus atos. Entende-se que esse ponto de vista é fundamental para estabelecer uma prática dialógica entre todos os envolvidos no processo da adolescência: jovem, colegas, família, comunidade, escola e serviço de saúde.

\section{Referências}

BRASIL. Ministério da Saúde. Manual de controle das doenças sexualmente transmissíveis. Brasília, 1997a.

Ministério da Saúde. Coordenação Nacional de Doenças Sexualmente

Transmissíveis e Aids. Manual do multiplicador: adolescente. 2. ed. Brasília, 1997b.

. Ministério da Educação e do Desporto. Secretaria de Educação Fundamental.

Parâmetros Curriculares Nacionais: pluralidade cultural e orientação sexual. Brasília, 1997c.

BUENO, S. M. V. Educação preventiva em sexualidade, DST-AIDS e drogas nas escolas. 2001. 223f. Tese (Livre docência) - Escola de Enfermagem de Ribeirão Preto, Universidade de São Paulo, Ribeirão Preto, 2001.

CARDOSO, C. P.; COCCO, M. I. M. Projeto de vida de um grupo de adolescentes à luz de Paulo Freire. Revista Latino-americana de Enfermagem, Ribeirão Preto, v. 11, n. 6, p. 778-785, 2003.

FREIRE, P. Extensão ou comunicação? 11. ed. Rio de Janeiro: Paz e Terra, 2001.

Pedagogia do oprimido. 29. ed. São Paulo: Paz e Terra, 2000.

Educação como prática da liberdade. 22. ed. Rio de Janeiro: Paz e Terra, 1996 a.

Pedagogia da autonomia: saberes necessários à prática educativa. 30. ed. Rio de

Janeiro: Paz e Terra, 1996b. 
Alencar, R. A. et al.

Educação na cidade. São Paulo: Cortez, 1995.

GALVÃO, M. T. G.; FERREIRA, M. L. S. M.; ALENCAR, R. A. Sexualidade e conhecimento das doenças sexualmente transmissíveis e Aids entre adultos em um município do interior do nordeste brasileiro. Jornal Brasileiro de DST, Rio de Janeiro, v. 15 , n. 3, p. $37-40,2003$.

HERCOWITZ, A. Gravidez na adolescência. Pediatria moderna, São Paulo, v. 38, n. 8, p. 392-395, 2002.

LIMA, C. T. B. et al. Percepções e práticas de adolescentes grávidas e de familiares em relação à gestação. Revista Brasileira de Saúde Materno Infantil, Recife, v. 4, n. 1, p. 71-83, 2004.

LOURENCINI JÚNIOR, A. Os sentidos da sexualidade: natureza, cultura e educação. In: AQUINO, J. G. Sexualidade na escola: alternativas teóricas e práticas. 3. ed. São Paulo: Summus, 1997. p. 87-95.

MACHADO, M. F. A. S. et al. Integralidade, formação de saúde, educação em saúde e as propostas do SUS: uma revisão conceitual. Ciência \& Saúde Coletiva, Rio de Janeiro, v. 12, n. 2, p. 335-342, 2007.

MEIRELLES, J. A. B. Os ETs e a gorila: um olhar sobre a sexualidade, a família e a escola. In: AQUINO, J. G. Sexualidade na escola: alternativas teóricas e práticas. 3. ed. São Paulo: Summus, 1997. p. 71-86.

MINAYO, M. C. S. Ciência, técnica e arte: o desafio da pesquisa social. In: Pesquisa social: teoria, método e criatividade. Petrópolis: Vozes, 1994. p. 9-29. (Org.).

NETO, O. C. O trabalho de campo como descoberta e criação. In: MINAYO, M. C. S. (Org.). Pesquisa social: teoria, método e criatividade. Petrópolis: Vozes, 1994. p. 51-66.

PINTO, H. D. S. A individualidade impedida: adolescência e sexualidade no espaço escolar. In: AQUINO, J. G. Sexualidade na escola: alternativas teóricas e práticas. 3. ed. São Paulo: Summus, 1997. p. 43-51.

SAYÃO, R. Saber o sexo? - os problemas de informação sexual e o papel da escola. In: AQUINO, J. G. Sexualidade na escola: alternativas teóricas e práticas. 3. ed. São Paulo: Summus, 1997. p. 97-105.

SILVA, A. F. G. Das falas significativas às práticas contextualizadas: a construção do currículo na perspectiva crítica e popular. 2004. 493f. Tese (Doutorado) - Pontifícia Universidade Católica de São Paulo, São Paulo, 2004.

TORRES, C. A.; O’ CADIZ, M. P.; WONG, P. L. Educação e democracia - a práxis de Paulo Freire em São Paulo. São Paulo: Cortez/Instituto Paulo Freire, 2002.

VITIELLO, N. A educação sexual necessária. Revista Brasileira de Sexualidade Humana, São Paulo, v. 6, n. 1, p. 15-28, 1995.

Artigo recebido em fevereiro de 2007 e aceito em setembro de 2007 